\title{
Effect of aerodynamic loads on redistribution of normal reactions of quarry dump trucks tires
}

\author{
Mikhail Dadonov ${ }^{l}$, Alexander Kulpin ${ }^{l}$, Valery Borovtsov ${ }^{l}$, and Anar Zhunusbekova ${ }^{2}$ \\ ${ }^{1}$ T.F. Gorbachev Kuzbass State Technical University, 650000 Kemerovo, 28 Vesennaya st., Russian \\ Federation \\ ${ }^{2}$ Kazakh Humanitarian Juridical Innovative University, EKR, Semey, 11Mangilik st., Republic of \\ Kazakstan
}

\begin{abstract}
Tires of quarry dump trucks occupy one of the leading places in the item of costs for motor transport, as they are expensive product and at the same time more than half of them do not generate their resource. The causes of premature tires failure are exceeding normal load on them. In turn, the aerodynamic forces effect on the quarry dump truck as one of the influencing factors, is the dynamic redistribution of normal loads on tires and, as a result, affects temperature modes. The determination of the load on the tire under different operating conditions will increase the service life of the tires and avoid early failure. The proposed calculation method of aerodynamic loads and their influence on redistribution of normal mine dump truck tires reactions in dynamics allows to make correction to load modes and control the tires resource, which will lead to more complete use of tires resource.
\end{abstract}

\section{Introduction}

Large and oversized tires of modern quarry dump trucks are operated in extremely heavy mining and climatic conditions. More than $50 \%$ of the tires in operation do not use the resource input by the manufacturer. Earlier our works were devoted to analysis of factors affecting temperature and load operation tires modes of mine dump trucks as well as determination of their influence degree. This article is devoted to the study of aerodynamic forces effect on the quarry dump truck as one of the factors affecting the dynamic redistribution of normal loads on tires, and therefore on their temperature conditions [1,2].

\section{Results and discussions}

Forces and moments of aerodynamic resistance arise as a result of an air flow impingement on the quarry truck during its movement. Their value is proportional to the square of the air flow impingement velocity, as well as depending on the shape and overall dimensions of the streamlined body. The air flow flowing onto the dump truck is the vector sum of the air flows that are result of the own speed of the dump truck movement and the wind speed. The 
own speed of the truck is rather low - not more than $10-12 \mathrm{~m} / \mathrm{s}$, but the wind speed can reach $15-20 \mathrm{~m} / \mathrm{s}$. In the opposing wind, the speeds of the quarry truck and wind sum up, however, there is generally a tilt flow of airflow at a certain angle. This angle is considered positive when the air flow impingement flows to the right dump truck side. In addition, quarry trucks are the bad streamlined vehicles and have large values of midline sections [3, $4,5]$.

Figure 1 shows the aerodynamic forces and moments acting on the quarry dump truck.

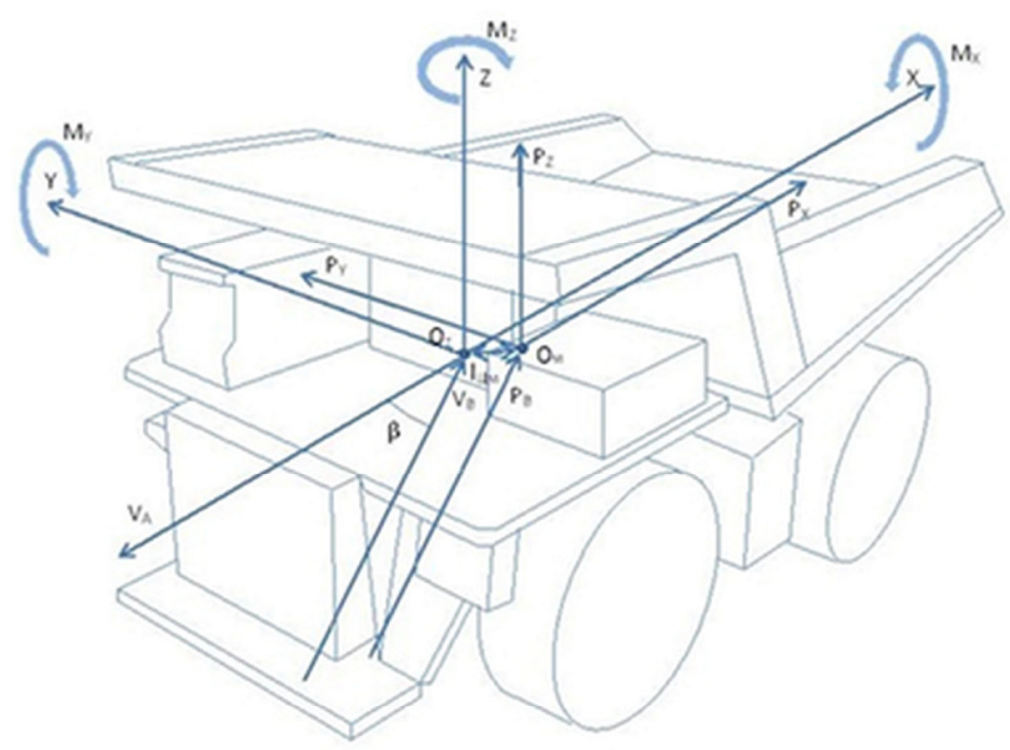

Fig. 1. Forces and moments of aerodynamic resistance, which arise when air flow impingement flows on a quarry dump truck.

where От - the the dump truck gravity centre;

$\mathrm{OM}_{\mathrm{M}}$ - meta-centre of full aerodynamic force application;

$\mathrm{V}_{\mathrm{A}}$ - dump truck movement speed vector;

$\mathrm{V}_{\mathrm{B}}-$ wind speed vector;

$\beta$ - angle between car movement direction and wind direction;

$\mathrm{P}_{\mathrm{B}}$ - full aerodynamic force;

$1_{Ц м}-$ baseline of the aerodynamic moment;

$\mathrm{M}_{\mathrm{B}}=\mathrm{P}_{\mathrm{B}} * 1_{ц м}$ - full aerodynamic moment;

$\mathrm{P}_{\mathrm{X}}$ - force of opposite aerodynamic resistance;

$\mathrm{PY}_{\mathrm{Y}}$ - tilt aerodynamic force;

$\mathrm{Pz}-$ aerodynamic lifting force;

$\mathrm{MX}_{\mathrm{X}}$ - heeling moment;

$\mathrm{My}$ - pitch moment;

$\mathrm{Mz}$ - yaw moment.

The air flow flows around the quarry dump truck, interacts with it, creating areas of increased and reduced pressure. This results a plurality of elementary aerodynamic forces acting on the surface of the truck. The total effect of all these elementary forces, the full aerodynamic force $\mathrm{P}_{\mathrm{B}}$, is applied to a certain point of the $Ц_{M}$ - the meta-center of the full aerodynamic force application. 


$$
P_{B}=0,5 C_{B} F \rho V_{A B}^{2}
$$

where $\mathrm{C}_{\mathrm{B}}$ - total aerodynamic force coefficient,

$\mathrm{F}$ - surface area of midline section,

$\rho$ - air density,

$\mathrm{V}_{\mathrm{AB}}-$ vector sum of dump truck and wind speeds.

Coordinates of the meta-centre location depend on the shape of the truck, on the value of longitudinal and transverse midline sections, on the presence or absence of cargo in the body, on the angle of air flow $[6,7,8]$.

In case coordinates of meta-center do not coincide with coordinates of the truck gravity centre, arm is formed equal to distance between gravity center and meta-center. Therefore, the total aerodynamic force applied to the meta-center produces the total aerodynamic moment $\mathrm{M}_{\mathrm{B}}$.

$$
M_{B}=0,5 m_{B} F \rho V_{A B}^{2} \bar{B}
$$

where $\mathrm{M}_{\mathrm{B}}$ - coefficient of total aerodynamic moment,

Б - characteristic size, which in our case, depending on the direction of the air flow impingement, may be either the wheel track or the base of the truck.

This moment can be decomposed by vectors along longitudinal, transverse and vertical axes $\mathrm{X}, \mathrm{Y}$ and $\mathrm{Z}$, mutually perpendicular and passing through the truck gravity center. Each of the resulting moments $\mathrm{M}_{\mathrm{X}}, \mathrm{M}_{\mathrm{Y}}, \mathrm{M}_{\mathrm{Z}}$ acts around a corresponding axis.

As a result of the roll moment action $\mathrm{M}_{\mathrm{X}}$, normal reactions are redistributed between the tires of the right and left side of the truck. When the angle $\beta$ is positive, the left side of the truck is unloaded and the right side is loaded.

$$
M_{X}=0,5 m_{X} F \rho V_{A B}^{2} B
$$

where $\mathrm{mX}$ - coefficient of aerodynamic heeling moment,

$\mathrm{B}$ - wheel track of rear (twin) wheels of quarry dump truck.

Pitch moment $\mathrm{M}_{\mathrm{Y}}$ redistributes loads between tires of front and rear axles of quarry dump trucks. Counter airflow additionally loads the rear axle of the truck and reduces load on the front one in the same volume. The associated wind leads to the opposite result.

$$
M_{Y}=0,5 m_{Y} F \rho V_{A B}^{2} l_{\kappa}
$$

where $m_{Y}-$ coefficient of aerodynamic pitch moment,

$1_{\mathrm{K}}-$ wheelbase of the quarry truck.

The yaw moment $\mathrm{M}_{\mathrm{Z}}$ tends to turn the dump truck perpendicular to the airflow direction. At the same time in wheels contact spot with road surface due to friction there are transverse reactions, which prevent removal of truck from the specified direction. This moment does not affect the redistribution of normal reactions between the wheels of the truck, so in the future we will not consider it.

Thus

$$
\begin{aligned}
M_{B} & =\sqrt{M_{X}^{2}+M_{Y}^{2}} \\
m_{B} & =\sqrt{m_{X}^{2}+m_{Y}^{2}}
\end{aligned}
$$


Consider two opposite cases.

$\beta=0$, i.e. the wind speed vector is directed strictly towards the vector of moving dump truck speed:

In this case $\mathrm{M}_{\mathrm{X}}=0, \mathrm{~V}_{\mathrm{AB}}=\mathrm{V}_{\mathrm{A}}+\mathrm{V}_{\mathrm{B}}$, and the truck projection surface area onto the plane $\mathrm{YZ}$ acts as the midsection area.

$$
F=B_{A}\left(H_{A}-h\right)+4 h b_{u}
$$

where $\mathrm{B}_{\mathrm{A}}$ - overall width of dump truck,

$\mathrm{H}_{\mathrm{A}}$ - overall height of dump truck,

$\mathrm{h}$ - distance from bumper to road surface,

$\mathrm{b}_{\amalg}-$ wheel width with tire.

Then the value of normal reactions on the truck rear axle wheels will increase by

$$
\Delta Z_{\text {rear }}=\frac{M_{Y}}{l_{K}-a}=\frac{0.5 m_{Y}\left[B_{A}\left(H_{A}-h\right)+4 h b_{u}\right] \rho\left(V_{A}+V_{B}\right)^{2} l_{K}}{l_{K}-a}
$$

and on the wheels of the front axle decreases by

$$
\Delta Z_{\text {front }}=\frac{M_{Y}}{l_{K}-b}=\frac{0.5 m_{Y}\left[B_{A}\left(H_{A}-h\right)+4 h b_{u l}\right] \rho\left(V_{A}+V_{B}\right)^{2} l_{K}}{l_{K}-b}
$$

where a-distance from the truck gravity center to the front axle,

$\mathrm{b}$ - distance from the truck gravity center to the rear axle.

$\beta=90^{\circ}$, i.e. the wind speed vector is directed strictly perpendicular to the speed vector of the moving dump truck:

In this case, the load redistribution on the tyres of the truck front and rear axles will be due to the air pressure which depends on its speed, and the wind speed will only affect the distribution of normal loads on its sides. In this case the area of the midsection is determined by the truck projection onto the $\mathrm{XZ}$ plane.

$$
\begin{gathered}
F=0.8 L_{A} H_{A} \\
\Delta Z_{\text {left,right }}=\frac{2 M_{X}}{B}=\frac{2 * 0.5 m_{X}\left[0.8 L_{A} H_{A}\right] \rho V_{B}^{2} B}{B} \\
\Delta Z_{\text {left,right }}=0,8 m_{X} L_{A} H_{A} \rho V_{B}^{2}
\end{gathered}
$$

where $\mathrm{L}_{\mathrm{A}}-$ overall length of dump truck.

When the value of angle $0<\beta<90$ changes, the values of the flow rate of the air flow and the midsection area will change.

$$
F=\left[B_{A}\left(H_{A}-h\right)+4 h b_{u}\right] \cos \beta+\left(0.8 L_{A} H_{A}\right) \sin \beta
$$

Total speed of an air flow for definition $\Delta \mathrm{Z}_{\text {rear }}$ and $\Delta \mathrm{Z}_{\text {front }}$ will be defined as

$$
V_{A B}=V_{A}+V_{B} \cos \beta
$$


It is necessary $\left(V_{\mathrm{B}} \sin \beta\right)$ for definition of $\Delta Z_{\text {left,right }}$.

\section{Conclusion}

The practical definition and consideration of the aerodynamic loads effect on the redistribution of normal mine truck tires reactions in dynamics is quite labour-intensive and complex process. However, it is obvious that this factor is important in the forming temperature modes process of operation of large-size and above-large tires of quarry trucks, so this issue requires further comprehensive study and assessment [9-16].

\section{References}

1. A. G. Kulpin, D. V. Stenin, E. E. Kultayev, E. E. Kulpina, V. A. Borovtsov, Coal in the 21st Century: Mining, Processing and Safety, 1 (2016)

2. D. V. Stenin, N. A. Stenina, A. A. Bakanov, Coal in the 21 st Century: Mining, Processing and Safety, 1 (2016)

3. X. Yang, O. Olatunbosun, D. Garcia-Pozuelo, E Bolarinwa, SAE Technical Papers, 6, $76(2015)$

4. Q. Sunqing, D. Junxiu, Ch. Guoxu, Lubricating Science, 11:3, 165 (1999)

5. A. A Samarskii, V. A Galaktionov, S. P Kurdiumov, A.P. Mikhailow, Blow-up in quasilinear parabolic equations (Berlin, Walter de Gruytel, 1995)

6. A. Abramovich, E Pudov, E Kuzin, E3S Web of Conferences, 21, 01011 (2017)

7. A. Kvasova, B. Gerike, E. Murko, D. Skudarnov. E3S Web of Conferences, 21, 03016 (2017)

8. F. Zhang, Z., Gu, S. Zhang, X. Ma, Zhu, Y. Chongji, Journal of Vibration and Shock, 35:17, 71 (2016)

9. T. H. Langer, T. K. Iversen, O.O. Mouritsen, M.K. Bak, M.R. Hansen, International Journal of Vehicle Design, 65:2-3, 222 (2014)

10. J. Meech, J. Parreira, IFAC Proceedings Volumes, 15:1, 142 (2013)

11. Y. Li, W.Y. Liu, S. Frimpong, Engineering Failure Analysis, 23, 55 (2013)

12. R. Larson, J. Cuadrado, SAE International Journal of Commercial Vehicles, 5:1, 101 (2012)

13. K. Pal, T. Das, Polymer Engineering and Science, 48:12, 2410 (2008)

14. T. Eguchi, T. Muro, 15th International Conference of the International Society for Terrain Vehicle Systems, 15, 23 (2005)

15. P. F. Knights, A. L. Boerner, Mining Engineering, 53:8, 51 (2001)

16. D. M. Dubinkin, Mining Equipment and Electromechanics, 6, 8 (2019) 